\title{
THỰC HÀNH VỀ PHÒNG TRÁNH NHIỄM ĐộC CHÌ CHO TRẺ EM TẠI MộT LÀNG NGHỀ THUộC TỈNH BẮC NINH
}

\section{TÓM TẮT.}

Mục tiêu: Đánh giá việc thực hành về phòng tránh nhiếm độc chì cho trẻ em của người dân tại một làng nghề thuộc tỉnh Bắc Ninh. Phương pháp nghiên cứu: 212 đối tượng (165 người chăm sóc trẻ và 47 trẻ em (10-14 tuổi) được quan sát, đánh giá về biện pháp phòng tránh nhiễm chì cho trẻ. Kết quả: $49,1 \%$ người có thực hành đạt về phòng tránh nhiễm độc chì cho trẻ em (Nhắc nhở trẻ về phòng tránh nhiếm độc chì của người trong gia đình của trẻ; phòng tránh nhiễm độc chì cho trẻ khi chăm sóc trẻ; thực hành đúng trong việc sử dụng thuốc cam cho trẻ; thực hành đúng của người có tiếp xúc với chì tại nơi làm việc và đang sống cùng trẻ). Kết luận: người dân tại một làng nghề thuộc tỉnh Bắc Ninh đã có một số một số người thực hành đạt về phòng chống nhiếm độc chì cho trẻ nhưng còn hạn chế.

Tư khoá: Thực hành, nhiễm độc chì, trẻ em, làng nghề, Bắc Ninh

\section{SUMMARY}

\section{LEAD POISONING CHILDREN'S} PREVENTION PRACTICE OF PEPLE IN ONE VILLAGE IN BAC NINH PROVINCE

Objectives: to evaluate about lead poisoning prevention practices for children of people in a craft village of Bac Ninh province. Methods: 212 subjects (165 caregivers and 47 children (10-14 years old)) were observed and evaluated for lead-contamination prevention measures for children. Results: $49.1 \%$ of people with good practice in preventing lead poisoning for children (Remind children about prevention of lead poisoning in their family; prevention of lead poisoning for children while taking care of children; correct practices in the use ofeEthnic medicine for children; correct practices for people who have been exposed to lead in the workplace and living with children). Conclusion: people in a craft village in Bac Ninh province have a number of practitioners that have achieved lead poisoning prevention for children, but they are still limited.

Keywords: Practice, lead poisoning, children, craft villages, Bac Ninh

\section{I. ĐĂT VẤN ĐỀ}

Trong các chất gây ô nhiễm môi trường thì chì là một trong những kim loại nặng, có độc tính cao và rất nguy hiểm đối với cơ thể con

*Viện Sức khỏe nghề nghiệp và Môi trường Chịu trách nhiệm chính: Nguyễn Đức Sơn Email: ducson199@gmail.com

Ngày nhận bài: 10.6.2021

Ngày phản biện khoa học: 10.8.2021

Ngày duyệt bài: 17.8.2021

\section{Nguyễn Đức Sơn*, Nguyễn Thu Hà*}

người, đặc biệt ở trẻ em. Nguy cơ tiếp xúc ở trẻ cũng cao hơn do sự tò mò bẩm sinh của trẻ em và hành vi đưa tay vào miệng dẫn đến việc trẻ nuốt những thứ bị nhiễm chì, như đất, bụi ô nhiễm [1], [2]. Các nghiên cứu ở trẻ em cho thấy chỉ số IQ giảm khoảng 5 điểm ở mức chì máu là $50-70 \mu \mathrm{g} / \mathrm{dL}$, giảm $1-2$ điểm ở mức chì máu từ $15-30 \mu \mathrm{g} / \mathrm{dL}$ [3].

Nghiên cứu những trẻ em từ khi sinh đến 7 tuổi ở vùng Port Pirie (gần với khu vực luyện chì ở Australia) cho thây hàm lượng chì máu có liên quan nghich đến chỉ số IQ ở tất cả các lứa tuổi trong khoảng từ 2 tuổi trở lên. Ở trẻ 2 tuổi, chỉ số thông minh giảm 1,6 điểm nếu hàm lượng chì máu tăng lên $10 \mu \mathrm{g} / \mathrm{dL}$. Ở trẻ 6 tuổi, chỉ số thông minh giảm 7,2 điểm nếu hàm lượng chì máu tăng từ $10-30 \mu \mathrm{g} / \mathrm{dL}$ và ở trẻ 7 tuổi thì chỉ số này giảm 4,4 - 5,3 điểm với mức tăng chì máu tương tự [4].

Cùng với giảm chỉ số IQ, người ta nhận thấy trẻ em bị nhiểm độc chì giảm khả năng chú ý, rối loạn chức năng ngôn ngữ, rối loạn khả năng tiếp nhận các chương trình giáo dục và khả năng thích nghi với môi trường nhà trường [5].

Để phòng tránh nhiễm độc chì cho trẻ thì cha, me của trẻ, những người chăm sóc trẻ (NCST) chính và bản thân trẻ cần phải thực hành đúng về phòng tránh nhiễm độc chì cho trẻ em.

Mục tiêu nghiên cứu: Đánh giá việc thực hành về phòng tránh nhiễm độc chi cho tré em của người dân tại một làng nghề thuộc tỉnh Bắc Ninh.

\section{II. ĐỐI TƯỢNG VÀ PHƯƠNG PHÁP NGHIÊN CỨU}

2.1. Đối tượng nghiên cứu. 212 đối tượng (165 người chăm sóc trẻ và 47 trẻ em (10-14 tuổi) sống tại một làng nghề thuộc tỉnh Bắc Ninh

\subsection{Phương pháp nghiên cứu}

- Thiêt kế nghiên cứu: Nghiên cứu mô tả cắt ngang

- Phương pháp chọn mẫu: chọn ngẫu nhiên đối tượng tham gia nghiên cứu từ danh sách các hộ gia đình từ danh sách hộ gia đình có trẻ từ 314 tuổi đang sống tại làng nghề và tiến hành quan sát, đánh giá việc thực hành về phòng tránh nhiễm độc chì cho trẻ em của người dân.

- Các chỉ số nghiên cứu

Quan sát, đánh giá việc thực hành về phòng tránh nhiễm độc chì cho trẻ em của người dân 
Thực hành của đối tượng nghiên cứu: đánh giá qua 04 nhóm hành vi chính:

- Nhắc nhở trẻ về phòng tránh nhiễm độc chì của người trong gia đình của trẻ: 04 nội dung nhắc nhở được đưa ra, có thực hiên thường xuyên việc nhắc nhở với từ 03 nội dung trở lên $\rightarrow$ được 1 điểm.

- Thực hành phòng tránh nhiễm độc chì cho trẻ khi chăm sóc trẻ: 07 thực hành đúng được đưa ra, thường xuyên thực hiện từ 04 thực hành đúng trở lên $\rightarrow$ được 1 điểm.

- Thực hành trong viêc sử dung thuốc cam cho trẻ: được 01 điểm nếu không sử dụng hoặc có sử dụng nhưng thuốc cam được mua ở cửa hàng có địa chỉ rõ ràng, uy tín.

- Thực hành của người có tiếp xúc với chì tại nơi làm việc và đang sống cùng trẻ: 05 thực hành đúng được đưa ra, chọn từ 3 thực hành đúng trở lên $\rightarrow$ được 1 điểm. Người khồng tiếp xúc, không tính điểm.

$\rightarrow$ Với đối tượng có tiếp xúc với chì: Điểm thực hành tối đa là 04 điểm. Đối tượng được đánh giá là có Thực hành đạt nếu tổng số điểm đạt $\geq 3$ điểm.

$\rightarrow$ Với đối tượng không tiếp xúc với chì: Điểm thực hành tối đa là 03 điểm (đối với người có tiếp xúc với chì). Đối tượng được đánh giá là có Thực hành đạt nếu tổng số điểm đạt $\mathbf{2} \mathbf{2}$ điểm.

2.3. Đạo đức trong nghiên cứu: tuân thủ đầy đủ các vấn đề y đức trong nghiên cứu theo Hội đồng y đức Viện Sức khỏe nghề nghiệp và môi trường - Bộ $Y$ tế phê duyệt

2.5 Xử lý số liệu: - Làm sạch thô bằng cách kiểm tra các phiếu trả lời, loại bỏ những phiếu bỏ trông $>50 \%$ thông tin.

- Nhập liệu bằng phần mềm Epidata

- Xử lý số liệu bằng phần mềm SPSS

\section{KẾT QUẢ NGHIÊN CỨU}

3.1. Thông tin chung vê đối tượng nghiên cứu. Nghiên cứu có sự tham gia của 212 đối tượng, trong đó $77,8 \%$ là NCST và 47 trẻ em từ 10-14 tuổi (sau đây goi tắt là nhóm trẻ em, chiếm $22,2 \%)$. Đa số người tham gia nghiên cứu là nữ (chiếm $89,1 \%$ trong nhóm NCST và $55,3 \%$ trong nhóm trẻ em) (Hình 3.1). Hình 3.2 cho thấy phân bố nhóm tuổi của 212 trẻ từ 3-14 tuổi tại các hộ gia đình tham gia nghiên cứu, có $25,9 \%$ trẻ dưới 6 tuổi, 44,3\% trẻ từ $6-10$ tuồi và $29,7 \%$ trẻ từ $11-14$ tuổi.

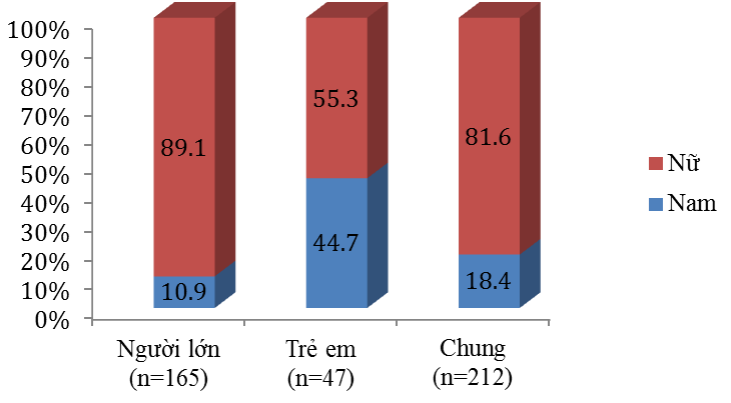

Hình 3. 1. Phân bố giới tính của đôî tượng tham gia nghiên cứu

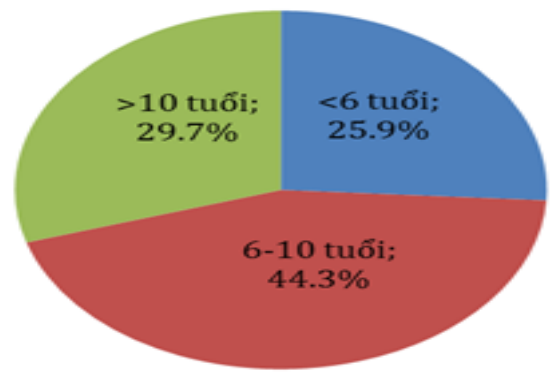

Hinh 3. 2. Phân nhóm tuổi của trẻ

3.2. Thực hành phòng tránh nhiễm độc chì cho trẻ em. Có 163 người trả lời rằng trong gia đình có người có tiếp xúc với chì tại nơi làm việc và đang sống cùng trẻ từ 3-14 tuổi (chiếm $76,9 \%$ ). Tìm hiểu về thực hành phòng tránh nhiễm độc chì cho trẻ em của nhóm này, kết quả cho thấy có $87,8 \%$ nhóm này có rửa tay trước khi chế biến thức ăn; $79,6 \%$ giặt quần áo làm việc riêng với quần áo của trẻ và gia đình. Tỷ lệ không thay quần áo, giày dép, tắm rửa tại nơi làm việc chiếm $41 \%$ và thực hiện tất cả các việc trên chiếm 18,4\% (Hình 3.3).

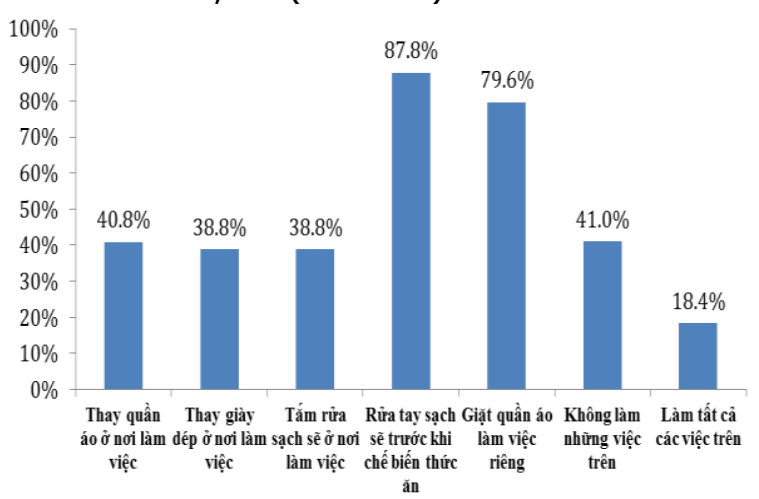

Hình 3. 3. Thực hành của người có tiếp xúc với chi tại nơi làm việc và đang sống cưng trẻ 
Bảng 1. Thực hành nhắc nhở trẻ về phòng tránh nhiếm độc chì của người trong gia đình của trẻ

\begin{tabular}{|c|c|c|c|c|c|c|c|}
\hline \multirow{2}{*}{$\begin{array}{l}\text { Nội dung } \\
\text { nhắc nhở }\end{array}$} & \multirow{2}{*}{$\begin{array}{l}\text { Tân suất } \\
\text { nhắc nhở }\end{array}$} & \multicolumn{2}{|c|}{ NCST $(n=165)$} & \multicolumn{2}{|c|}{ Trẻ em $(n=47)$} & \multicolumn{2}{|c|}{ Chung $(n=212)$} \\
\hline & & $\mathbf{n}$ & $\%$ & $\mathbf{n}$ & $\%$ & $\mathrm{n}$ & $\%$ \\
\hline \multirow{3}{*}{$\begin{array}{l}\text { Không nên chơi ở ở } \\
\text { những nở có thể } \\
\text { bị ô ôniếm chì }\end{array}$} & Không & 15 & 9,1 & 7 & 14,9 & 22 & 10,4 \\
\hline & Thinh thoảng & 60 & 36,4 & 21 & 44,7 & 81 & 38,2 \\
\hline & Thường xuyên & 90 & 54,5 & 19 & 40,4 & 109 & 51,4 \\
\hline \multirow{3}{*}{$\begin{array}{l}\text { Không được cho } \\
\text { tay, đồ chơi, đồ } \\
\text { dùng vào miệng }\end{array}$} & Không & 2 & 1,2 & 27 & 57,4 & 29 & 13,7 \\
\hline & Thinh thoảng & 42 & 25,5 & 15 & 31,9 & 57 & 26,9 \\
\hline & Thường xuyên & 121 & 73,3 & 5 & 10,6 & 126 & 59,4 \\
\hline \multirow{3}{*}{$\begin{array}{c}\text { Rửa tay trước khi } \\
\text { ăn }\end{array}$} & Không & 10 & 6,1 & 3 & 6,4 & 13 & 6,1 \\
\hline & Thinh thoảng & 56 & 33,9 & 21 & 44,7 & 77 & 36,3 \\
\hline & Thường $x$ & 99 & 60,0 & 23 & 48,9 & 122 & 57,5 \\
\hline \multirow{3}{*}{$\begin{array}{c}\text { Nguy cớ tác hại } \\
\text { của nhiếm độc } \\
\text { chì }\end{array}$} & Không & 118 & 71,5 & 31 & 66,0 & 149 & 70,3 \\
\hline & Có & 45 & 27,3 & 14 & 29,8 & 59 & 27,8 \\
\hline & Không nhớ & 2 & 1,2 & 2 & 4,3 & 4 & 1,9 \\
\hline
\end{tabular}

Bảng trên cho thấy có $51,4 \%$ người tham gia trả lời rằng người trong gia đình thường xuyên nhắc nhở trẻ không nên chơi ở những nơi có thể bị ô nhiễm chì; $59,4 \%$ thường xuyên nhắc nhở trẻ không được cho tay, đồ chơi, đồ dùng vào miệng; $57,5 \%$ thường xuyên nhắc nhở trẻ/ giúp trẻ rửa tay trước khi ăn. Tỷ lệ trẻ được người trong gia đình nói chuyện về nguy cơ, tác hại của nhiễm độc chì là $27,8 \%$.

Về việc sử dụng thuốc cam, có 17 người tham gia trả lời gia đình đã từng cho trẻ sử dụng thuốc cam (chiếm 8\%). Trong đó, 58,8\% thuốc được mua tại các cửa hành bán thuốc cam có địa chỉ rõ ràng và có uy tín; $23,5 \%$ mua theo địa chỉ người quen mách bảo và $17,7 \%$ mua tại chợ, không rõ nguồn gốc (Hình 3.4).

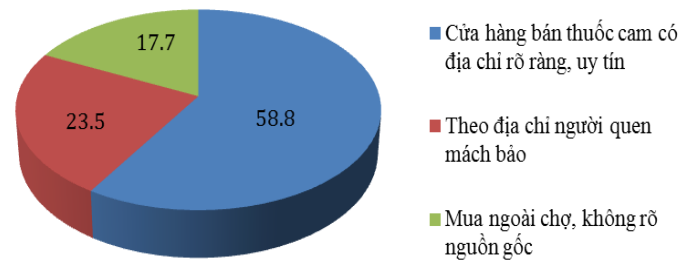

Hình 3.4. Nguồn gốc thuốc cam gia đình đã từng cho trẻ sử dùng

Bảng 2. Thực hành phòng tránh nhiễm độc chì cho trẻ khi chăm sóc trẻ

\begin{tabular}{|c|c|c|c|c|c|c|c|}
\hline \multicolumn{2}{|c|}{ Thực hành khi chăm sóc trẻ } & \multicolumn{2}{c|}{ NCST(n=165) } & \multicolumn{2}{c|}{ Trẻ em(n=47) } & \multicolumn{2}{c|}{ Chung(n=212) } \\
\cline { 3 - 8 } & $\mathbf{N}$ & $\mathbf{0}$ & $\mathbf{n}$ & $\mathbf{\%}$ & $\mathbf{n}$ & $\mathbf{\%}$ \\
\hline \multirow{3}{*}{$\begin{array}{c}\text { Mua đồ chơi cho } \\
\text { trẻ }\end{array}$} & Không mua vì tốn tiền & 46 & 27,9 & 20 & 42,6 & 66 & 31,1 \\
\cline { 2 - 8 } & Mua loại trẻ thích & 66 & 40,0 & 20 & 42,6 & 86 & 40,6 \\
\cline { 2 - 8 } & $\begin{array}{c}\text { Chì mua loại có nguồn } \\
\text { gốc rõ ràng, uy tín }\end{array}$ & 38 & 23,0 & 7 & 14,9 & 45 & 21,2 \\
\hline
\end{tabular}

Đánh giá chung về thực hành của 212 đối tượng tham gia nghiên cứu, cho thấy điểm thực hành trung bình của nhóm người chăm sóc trẻ là $2,7 \pm 0,9$ điểm, của nhóm trẻ em 11-14 tuổi là $2,4 \pm 0,4$ điểm. Tỷ lệ thực hành đạt chiếm 49,1\%, với $54,5 \%$ NCST và $29,8 \%$ trẻ em từ $11-14$ tuối (Hình 3.5).

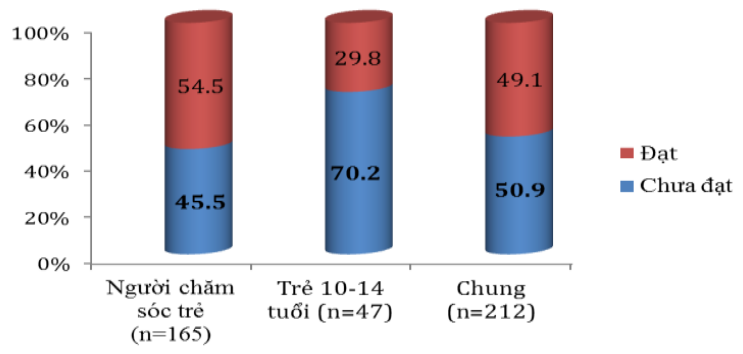

\begin{tabular}{|c|c|c|}
\hline $\begin{array}{c}\text { Nhóm đối } \\
\text { tượng }\end{array}$ & $\begin{array}{c}\text { Điếm } \\
\text { trung bình } \\
\text { 士 Độ lệ̂ch } \\
\text { chuấn }\end{array}$ & $\begin{array}{c}\text { Điếm thấp } \\
\text { nhất - } \\
\text { Điểm cao } \\
\text { nhất }\end{array}$ \\
\hline $\begin{array}{c}\text { Người chăm sóc } \\
\text { trẻ }(\mathrm{n}=165)\end{array}$ & $2,7 \pm 0,9$ & $1-4$ \\
\hline $\begin{array}{c}\text { Trẻ } 10-14 \text { tuối } \\
\text { (n=47) }\end{array}$ & $2,4 \pm 0,7$ & $1-4$ \\
\hline Chung (n=212) & $\mathbf{2 , 7 \pm 0 , 9}$ & $\mathbf{1 - 4}$ \\
\hline
\end{tabular}

Hình 3.5. Đánh giá chung về thực hành phòng tránh nhiếm độc chì cho trẻ của người dân Đa Hội 
VIETNAM MEDICAL JOURNAL N01 - SEPTEMBER - 2021

\begin{tabular}{|c|c|c|c|c|c|c|c|}
\hline & $\begin{array}{l}\text { Không quan tâm đến } \\
\text { nguồn gốc, xuất xứ }\end{array}$ & 19 & 11,5 & 2 & 4,3 & 21 & 9,9 \\
\hline & Khác & 5 & 3,0 & 0 & 0 & 5 & 2,4 \\
\hline \multirow{3}{*}{$\begin{array}{l}\text { Lau, rửa đồ chơi, } \\
\text { đồ dùng của trẻ }\end{array}$} & Không & 44 & 26,7 & 11 & 23,4 & 55 & 25,9 \\
\hline & Thinh thoảng & 36 & 21,8 & 29 & 61,7 & 122 & 57,5 \\
\hline & Thường xuyên & 28 & 17,0 & 7 & 14,9 & 35 & 16,5 \\
\hline \multirow{3}{*}{ Quét dọn nhà } & Không & 1 & 0,6 & 0 & 0 & 1 & 0,5 \\
\hline & Thinh thoảng & 36 & 21,8 & 14 & 29,8 & 50 & 23,6 \\
\hline & Thường xuyên & 128 & 77,6 & 33 & 70,2 & 161 & 75,9 \\
\hline \multirow{4}{*}{$\begin{array}{l}\text { Biên pháp giảm } \\
\text { phát tán bụi khi vệ } \\
\text { sinh nhà cửa }\end{array}$} & Không làm gì & 46 & 27,9 & 29 & 61,7 & 64 & 30,2 \\
\hline & Dùng chối, vải ướt & 110 & 66,7 & 33 & 70,2 & 143 & 67,5 \\
\hline & Vấy nước trước quét & 29 & 17,6 & 5 & 10,6 & 34 & 16,0 \\
\hline & Khác & 2 & 1,2 & 0 & 0 & 2 & 0,9 \\
\hline \multirow{3}{*}{$\begin{array}{l}\text { Rửa, lau chùi các } \\
\text { vật dụng trong nhà }\end{array}$} & Không & 2 & 1,2 & 4 & 8,5 & 6 & 2,8 \\
\hline & Thinh thoảng & 94 & 57,0 & 30 & 63,8 & 124 & 58,5 \\
\hline & Thường xuyên & 69 & 41,8 & 13 & 27,7 & 82 & 38,7 \\
\hline \multirow{3}{*}{ Cho trẻ ăn đủ chất } & Không & 10 & 6,1 & 0 & 0 & 10 & 4,7 \\
\hline & Thỉnh thoảng & 72 & 43,6 & 24 & 51,1 & 96 & 45,3 \\
\hline & Thường xuyênn & 83 & 50,3 & 23 & 48,9 & 106 & 50,0 \\
\hline \multirow{3}{*}{$\begin{array}{l}\text { Rửa tay với xà } \\
\text { phòng trước khi } \\
\text { chuẩn bị thức ăn/ } \\
\text { cho trẻ ăn }\end{array}$} & Khồng & 8 & 4,8 & 3 & 6,4 & 11 & 5,2 \\
\hline & Thinh thoảng & 65 & 39,4 & 26 & 55,3 & 91 & 42,9 \\
\hline & Thường xuyên & 92 & 55,8 & 18 & 38,3 & 110 & 51,9 \\
\hline
\end{tabular}

Bảng trên cho thấy có $40,6 \%$ người tham gia cho biết gia đình mua bất kỳ loại đồ chơi nào miễn là trẻ thích, $21,2 \%$ gia đình quan tâm đến nguồn gốc đồ chơi và chỉ mua cho trẻ loại có nguồn gốc rõ ràng, uy tín. Tỷ lê thường xuyên lau, rửa đồ chơi, đồ dùng của trẻ là $16,5 \%$. Có $75,9 \%$ người trả lời gia đình có thường xuyên quét dọn nhà cửa, $30,2 \%$ trả lời gia đình không dùng biện pháp gì để giảm phát tán bụi khi vệ sinh nhà cửa; thường xuyên cọ rửa, lau chùi các vật dụng trong nhà $(38,7 \%)$. Khi chăm sóc trẻ, tỷ lệ người trả lời rằng gia đình thường xuyên cho trẻ ăn đủ chất chiếm $50 \%$, người trong gia đình thường xuyên rửa tay bằng xà phòng trước khi chuẩn bị thức ăn hoặc khi cho trẻ ăn (51,9\%).

\section{BÀN LUÂNN}

4.1. Đặc điểm đối tượng nghiên cứu. Nghiên cứu có sự tham gia của 212 đối tượng, trong đó $77,8 \%$ là NCST chính và $22,2 \%$ trẻ em từ 10-14 tuổi (nhóm trẻ em). Điều này phù hợp với thực tế điều tra tại địa bàn nghiên cứu, khi gửi giấy mời đến hộ gia đình, thường là cha/ mẹ hoặc NCST chính sẽ tham gia, tuy nhiên có một số gia đình có trẻ lớn 10-14 tuổi, do cha/ mẹ trẻ do không thu xếp được thời gian tham gia phỏng vấn, nên đã đồng ý cho trẻ tham gia nghiên cứu. Nhóm NCST tham gia nghiên cứu chủ yếu là nữ chiếm $89,1 \%$ cũng phù hợp với thực tế mẹ hoặc bà của trẻ thường là NCST chính.

4.2. Thực hành về phòng tránh nhiễm độc chì cho trẻ em. Có $41 \%$ nhóm người có tiểp xúc với chì tại nơi làm việc và đang sống cùng từ 3-14 tuổi không thay quần áo, giày dép, tắm rửa tại nơi làm việc để dự phòng nhiểm chì cho trẻ. Kết quả này phản ánh thực tế tại hầu hết các cơ sở sản xuất liên quan đến chì chưa có/ không có khu riêng để công nhân có thể thay quần áo, giày dép, tắm rửa trước khi về nhà. Đồng thời, kết quả này cho thấy nguy cơ trẻ em bị phơi nhiễm với chì trên quần áo, cơ thể của người có tiếp xúc với chì tại nơi làm việc.

Tỷ lệ các gia đình thường xuyên nhắc nhở trẻ không nên chơi ở những nơi có thể bị ô nhiễm chì; không được cho tay, đồ chơi, đồ dùng vào miệng; rửa tay trước khi ăn còn chưa cao (chỉ khoảng $50 \%$ ). Đặc biệt, tỷ lệ gia đình đã từng nói chuyện về nguy cơ, tác hại của nhiễm độc chì cho trẻ chỉ chiếm $27,8 \%$. Kết quả này tương đồng với nghiên cứu của của Mahon I (1997) tại Philadelphia với 49\% NCST chính cho biết họ "không bao giờ" hoặc chỉ "đôi khi" thực hiện các hoạt động phòng chống nhiễm độc chì cho trẻ theo khuyến cáo [6].

Thực hành về vệ sinh phòng bệnh của những gia đình có trẻ 3-14 tuổi tham gia nghiên cứu còn hạn chế. Chỉ có $16,5 \%$ gia đình thường xuyên lau, rửa đồ chơi, đồ dùng của trẻ; $30,2 \%$ gia đình không dùng biện pháp gì để giảm phát tán bụi khi vệ sinh nhà cửa; 38,7\% gia đình thường xuyên cọ rửa, lau chùi các vật dụng 
trong nhà. Trong khi đó, một nghiên cứu tại Malaysia của tác giả Ab Razak NH năm 2015 cho thấy $81 \%$ thực hành tốt đối với phòng tránh ô nhiếm chì, kim loại nặng trong nước uống [7]. Khi chăm sóc trè, tỳ lệ người trả lời thường xuyên cho trẻ ăn đủ chất chiếm $50 \%$, thấp hơn so với $82,3 \%$ người lựa chọn cho trẻ ăn đủ chất, nhất là các khoáng chất như canxi, kẽm, ...là biện pháp phòng tránh nhiễm độc chì cho trẻ.

\section{KẾT LUẬN}

$49,1 \%$ người có thực hành đạt về phòng tránh nhiễm độc chì cho trẻ em (Nhắc nhở trẻ về phòng tránh niễ̂m độc chì của người trong gia đình của trẻ; phòng tránh nhiếm độc chì cho trẻ khi chăm sóc trẻ; thực hành đúng trong việc sử dụng thuốc cam cho trẻ; thực hành đúng của người có tiếp xúc với chì tại nơi làm việc và đang sống cùng trẻ).

\section{KHUYẾN NGH!}

Các tác giả khuyến nghị cần tăng cường triển khai các hoạt động truyền thông giáo dục sức khỏe dưới nhiều hình thức như tờ rơii, phát thanh trên loa, truyền thông trực tiếp tại trạm y tế và trường học, tư vấn/ giáo dục nhóm.... nhằm nâng cao kiến thức và thay đổi thái độ và thực hành về phòng tránh nhiễm độc chì cho trẻ em tại địa điểm nghiên cứu.

\section{TÀI LIÊUU THAM KHẢO}

1. Agency for Toxic Substances and Disease Registry (2010), "Case Studies in Environmental Medicine", Lead Toxicity.

2. Kim MA and Williams KA (2016), "Lead Levels in Landfill Areas and Childhood Exposure: An Integrative Review", Public Health Nurs.

3. Otto D.A. et al. (1981), "Effects of age and body lead burden on CNS function in young children. I. Slow cortical potentials", Electroencephalogr. Clin. Neurophysiol. 52, 229-239.

4. Kowetha A. Davidson (1994), Toxicity summary for lead (Inorganic). Oak Ridge Reservation Environmental Restoration Program, web http://rais.ornl.gov/tox/profiles/lead.doc.

5. Needleman H.L., et al. (1979), "Deficits in psychologic and classroom performance of children with elevated dentine lead level", New.Engl. J. Med. 300, 689-695.

6. Mahon I (1997), "Caregivers' knowledge and perceptions of preventing childhood lead poisoning", Public Health Nurs. 14(3), 169-182.

7. Ab Razak NH, et al. (2015), "Quality of Kelantan drinking water and knowledge, attitude and practice among the population of Pasir Mas, Malaysia", Public Health. 131, 103-111. 